\title{
ARSITEKTUR, MATERIAL BANGUNAN DAN KEHARMONISAN KEHIDUPAN
}

\author{
Andi Prasetiyo Wibowo \\ 1 Program Studi Arsitektur, Fakultas Teknik, Universitas Atma Jaya Yogyakarta \\ Kampus II Gedung Thomas Aquinas Jalan Babarsari 44 Yogyakarta \\ *Email: andiprasetiyo@staff.uajy.ac.id
}

\begin{abstract}
Architecture is not only focused on the physical stucture, but it contains many things that can be synergized, including nature and culture. That synergies were expected to create a work of architecture that is familiar and acceptable. From this premise, the term of eco-architecture known, that will help us create environmentally architectural masterpiece. There were Romo Mangun and Eko Prawoto that give us an understanding on how the architect and their work can be closer to nature and local cultures that exist in the location where the architect is putting their work. This works maybe not using building materials that are super luxurious and high tech. However, from the simplicity born an architectural works that have a 'soul'. Similarly as we as human beings, adapting the architecture to the environment will make the architecture may survive. Harmony of life will be created when the environment and architecture walk in harmony, coexistence and also mutual respect to each other. Architecture is not only focused on the physical stucture, but it contains many things that can be synergized, including nature and culture. That synergies were expected to create a work of architecture that is familiar and acceptable. From this premise, the term of eco-architecture known, that will help us create environmentally architectural masterpiece. There were Romo Mangun and Eko Prawoto that give us an understanding on how the architect and their work can be closer to nature and local cultures that exist in the location where the architect is putting their work. This works maybe not using building materials that are super luxurious and high tech. However, from the simplicity born an architectural works that have a 'soul'. Similarly as we as human beings, adapting the architecture to the environment will make the architecture may survive. Harmony of life will be created when the environment and architecture walk in harmony, coexistence and also mutual respect to each other.
\end{abstract}

Keywords: Eco-architecture, material building, local wisdom, harmony of life.

\section{PENDAHULUAN}

Arsitektur adalah seni dan ilmu dalam merancang bangunan. Dalam artian yang lebih luas, arsitektur mencakup merancang dan membangun keseluruhan lingkungan binaan, mulai dari level makro yaitu penataan kawasan, perencanaan dan perancangan kota, hingga ke level mikro yaitu desain bangunan, desain perabot dan desain produk.

Alam merupakan penunjang kehidupan, maka setiap kegiatan manusia seharusnya didasarkan pada pemahaman terhadap alam, termasuk pada dunia arsitektur. Pemahaman terhadap alam pada arsitektur adalah upaya untuk menyelaraskan rancangan dengan alam, yaitu melalui memahami perilaku alam, ramah dan selaras terhadap alam.
Budaya atau kebudayaan berasal dari bahasa Sansekerta yaitu buddhayah, yang merupakan bentuk jamak dari buddhi (budi atau akal) diartikan sebagai hal-hal yang berkaitan dengan budi dan akal manusia. Budaya tidak dapat dipisahkan dari kehidupan masyarakat karena semua aspek dalam kehidupan masyarakat dapat dikatakan sebagai wujud dari kebudayaan, misalnya gagasan atau pikiran manusia, aktivitas manusia, bahkan dapat berupa karya yang dihasilkan manusia.

Budaya tidak dapat dipisahkan dari sebuah negara, terlebih untuk Indonesia yang dikenal sebagai negara multikultural. Budaya lokal Indonesia beranekaragam, karena Indonesia terdiri dari banyak suku. Hal ini menjadi satu kebanggaan sekaligus suatu tantangan bagi seluruh rakyat Indonesia untuk 
dapat mempertahankan budaya lokal yang ada di tengah banyaknya pengaruh budaya asing yang dapat merusak budaya lokal. Banyaknya suku bangsa tersebut, juga melahirkan banyak karya arsitektural lokal sebagai bagian tak terpisahkan dari budaya itu sendiri yang terwujud dalam bentuk rumah-rumah adat/tradisonal.

\section{METODE PENELITIAN}

Arsitektur yang baik tidak harus arsitektur yang besifat monumental dan memiliki nilainilai keindahan dalam wujud kemewahan. Sadar atau tidak, para arsitek seringkali menciptakan karya arsitekturalnya untuk menunjukkan ke'aku'annya. Egois, tidak mau kalah, harus menonjol, menjadi hal-hal yang menjadi pertimbangan dalam menciptakan suatu karya arsitektural. Kekhasan suatu bentuk bukan merupakan hal yang haram dalam dunia arsitektur, namun bagaimana mengolah kekhasan tersebut menjadi hal yang tetap menselaraskan alam dan budaya sekitar. Alam dan budaya sudah ada terlebih dahulu dibandingkan lahirnya arsitektur, sebagai pendatang sudah sepantasnya arsitekturlah yang mengkuti apa yang sudah ada sebelumnya. Beradaptasilah dengan lingkungan sekitar, maka kita akan menciptakan kenyamanan bagi diri kita sendiri. Dengan demikian terciptalah keharmonisan kehidupan, karena adanya rasa saling hormat antar elemen kehidupan tersebut.

Tulisan ini akan membahas tiga hal di atas sebagai satu kesatuan yang dapat saling mendukung dan melengkapi, sehingga nantinya akan dapat menambah wawasan dan kesadaran kita akan pentingnya arsitektur yang mempertimbangkan kelestarian alam dan tetap memperhatikan budaya lokal. Dalam tulisan ini pula akan diulas mengenai 2 buah karya arsitektural dari 2 tokoh arsitektural anak negeri ini yang setidaknya bisa memberi gambaran konkret mengenai konsep keharmonisan kehidupan melalui arsitektur.

\section{HASIL DAN PEMBAHASAN}

\section{Eko-Arsitektur \\ Kelestarian Alam}

Arsitektur ekologis atau eko-arsitektur adalah pembangunan rumah atau tempat tinggal sebagai kebutuhan kehidupan manusia dalam hubungan timbal balik dengan lingkungan alamnya (Frick, 1997). Kualitas arsitektur biasanya hanya memperhatikan bentuk bangunan dan konstruksinya, tetapi mengabaikan yang dirasakan si pengguna dan kualitas hidupnya.

Eko-arsitektur sebenarnya merupakan istilah holistik yang sangat luas dan mencakup banyak bidang, di antaranya arsitektur biologis (arsitektur kemanusiaan yang memperhatkan kesehatan), arsitektur alternatif, arsitektur surya/matahari (pemanfaatan energi surya), arsitektur bionik (teknik sipil dan konstruksi ekologis yang memperhatikan kesehatan manusia), biologi pembangunan.

Menurut Frick (1997, hlm. 27) pola perencanaan eko-arsitektur adalah sebagai berikut:

1. Holistis, berhubungan dengan sistem keseluruhan, sebagai bagian suatu kesatuan yang lebih penting daripada sekedar kumpulan bagian,

2. Memanfaatkan pengalaman manusia (tradisi dalam pembangunan) dan pengalaman lingkungan alam terhadap manusia,

3. Pembangunan sebagai proses dan bukan sebagai kenyataan tertentu yang statis,

4. Kerja sama antara manusia dengan alam sekitarnya demi keselamatan kedua belah pihak

\section{Pelestarian dan Pengembangan Budaya Lokal Dalam Arsitektur}

Kita boleh saja hidup di dunia modern, namun bukan berarti hal-hal yang bersifat tradisional lantas ditinggalkan begitu saja. Eko Agus Prawoto atau yang lebih sering disebut Eko Prawoto -arsitek peraih IAI Award 2002 untuk Rumah Cemeti Yogyakarta- dalam sebuah wawancara yang dilakukan oleh Halimatussadiyah dan Yoenazh K. Azhar (wartawan Housing Estate) di sela-sela Jakarta Architecture Triennale 2009 di Jakarta, mengatakan bahwa "masyarakat tradisional menganggap alam sebagai ibu. Mana ada orang yang menyengsarakan ibunya? Berkebalikan dengan manusia modern yang memandang alam sebagai sumber daya (eksploitatif)". Dari pernyataan tersebut, kita melihat sebuah pemikiran yang masih dipegang oleh masyarakat tradisional dalam menyikapi hal-hal di dalam kehidupannya, termasuk dalam menciptakan hunian dan lingkungan tempat tinggal mereka. Bahan tradisional dari alam; tanah liat, bambu, kayu, ranting bisa tahan lama dan dapat dipakai dengan gampang dan murah. 
Ini merupakan pengalaman rakyat yang berabad-abad mengendap dalam suatu tradisi membangun yang telah lama dimiliki oleh bangsa kita. Putra, R. H., \& Prijotomo, J. (2016) dalam makalahnya memberikan contoh mengenai penggunaan material lokal berupa bambu yang diwujudkan dalam karya arsitektur Bengkel Bambu Menoreh yang merupakan sebuah objek arsitektural yang merespon isu tentang kesadaran akan material bambu untuk bangunan arsitektural di Indonesia. Penggunaan material dan tenaga lokal pada pembangunan Gereja Puh Sarang, Kediri juga merupakan sebuah indikasi pelestarian dan pengembangan budaya lokal (Hartanti, G. (2011).

YB Mangunwijaya dalam bukunya 'Wastu Citra' (1988), menekankan pula bahwa kearifan budaya lokal mampu menjadi solusi desain yang 'membumi', ramah lingkungan dan lebih bersifat 'abadi'. Pemikiran menyeluruh dan kontekstual, paduan seimbang logika, intuisi dan kreativitas serta muatan sosial budaya desain terangkum pula dalam pemikiran 'guna dan citra'. Berdasar kata aslinya, 'guna' tidak hanya berarti bermanfaat atau mendapatkan keuntungan materiil belaka, tetapi lebih dari pada itu punya daya yang menyebabkan hidup dapat lebih meningkat. Dalam arsitektur, 'guna' menunjukkan suatu fungsi baik secara fisik maupun psikis yang dapat membuat penghuni sebuah bangunan dapat lebih nyaman dan terlindung dari pengaruh cuaca panas dan dingin. Sedangkan 'citra' menunjukkan suatu gambaran/image, yakni suatu kesan penghayatan yang menangkap arti bagi seseorang. Pada dasarnya 'citra' tidak berbeda dengan 'guna', tetapi lebih pada tingkat spiritual, lebih menyangkut derajat dan martabat manusia yang tinggal di dalamnya. 'Citra' merupakan jiwa yang mengekspresikan keindahan, kewajaran, kejujuran dan budi bahasa tinggi. 'Citra' juga merupakan lambang yang membahasakan segala yang manusiawi. Dengan demikian bila 'guna' lebih menunjuk pada peradaban, maka 'citra' menunjuk pada kebudayaan.

Pemikiran Mangunwijaya yang kontekstual, peka terhadap kearifan lokal, 'membumi' diwujudkan dalam karya-karyanya seperti area ziarah umat Katolik di Sendang Sono, Muntilan, Pertapaan Bunda Pemersatu Gedono, di sebelah barat daya Salatiga, ataupun pemukiman tepi Kali Code, Yogyakarta. Kejujuran fungsi, bahan dan struktur menentukan estetika bentuk bangunan dan kawasan karya Mangunwijaya yang menunjukkan kesatuan dengan alam dan merupakan konsistensi perwujudan konsep guna dan citra yang dicetuskannya.

\section{Pertapaan Bunda Pemersatu Gedono}

Pertapaan Bunda Pemersatu Gedono adalah pertapaan rubiah pertama Ordo Cistersiensis Observasi Ketat (OCSO) atau umumnya disebut Trappist di Indonesia. Rubiah merupakan pertapa perempuan dalam agama Katolik (jika pertapa pria disebut rahib. Rubiah bisa juga dideskripskan sebagai suster/ biarawati yang mengkhususkan diri pada kegiatan bertapa/ berdoa). Gedono terletak di sebelah barat daya Salatiga, tepatnya di dukuh Weru, Desa Jetak, Kecamatan Getasan, Kabupaten Semarang.

Dalam karya-karyanya, termasuk di Gedono ini, Romo Mangun (panggilan akrab Y.B. Manguwijaya) selalu menekankan tiga hal, yaitu pertama, rancangannya lebih terlihat sebagai suatu kesinambungan, bukan perlawanan terhadap alam. Ruang-ruang di dalam dan luar saling menembus dengan lembut, bangunan dan halaman berhubungan secara erat. Kedua, hampir semua bangunan yang dibangun Romo Mangun memperlihatkan pemahaman Romo Mangun pada arsitektur tradisional daerah tropis yang lembab seperti Indonesia. Proses pelokalan yang dilakukan Romo Mangun menitikberatkan pada aspekaspek tektonika materi di daerah tropis lembab (Kusbiantoro, 2013). Ketiga, penyatuan kreasi manusia dengan alam diperlihatkan dengan penggunaan bahan-bahan lokal dan alami, seperti batu, kayu, dan bambu. Hampir seluruh karya Romo Mangun dibentuk dari sikap hormatnya pada bahan-bahan alam dan bagaimana memperlakukannya. Di beberapa rancangannya, sengaja maupun tidak, Romo Mangun harus berurusan dengan tanah-tanah berkontur baik di lingkungan pedesaan maupun di kota. Kontur tanah tersebut tidak dapat dipisahkan dengan penampilan karyanya, baik sebagai upaya menyelaraskan dengan sekitarnya maupun untuk menghindari masalah-masalah teknis. 


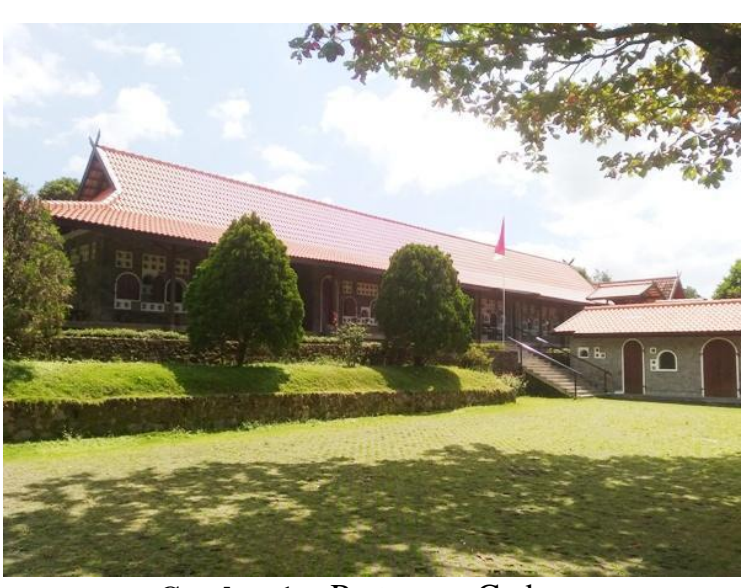

Gambar 1. Pertapaan Gedono

Sumber: Begini Heningnya, 2016

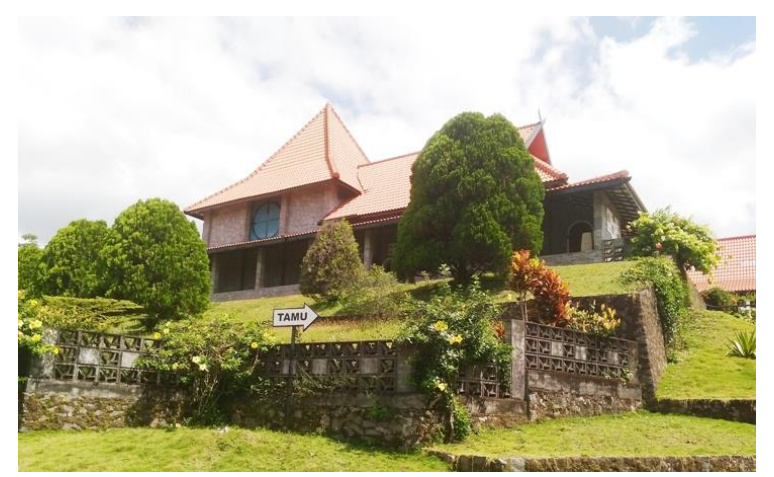

Gambar 2. Pertapaan Gedono di bangun di atas tanah berkontur

Sumber: Begini Heningnya, 2016

Bentuk atap bangunan segi empat selalu dirancang dengan kemiringan yang curam hingga bersudut $60^{\circ}$. Dinding sebagai penutup ruang menjadi wahana untuk bermain-main dengan pelubangan-pelubangan yang kadang sangat terkesan sebagai ornamen, tetapi tidak jarang sebagai pemanfaatan dan kamuflase dari sambungan-sambungan antar elemen bangunan.

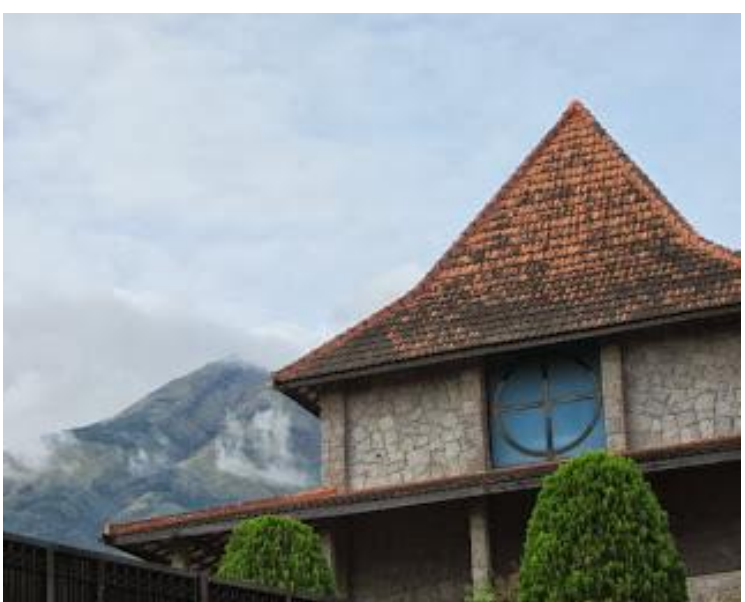

Gambar 3. Sudut atap dengan kemiringan yang curam sebagai ciri khas bangunan daerah tropis Sumber: Kisah Ziarah, 2013

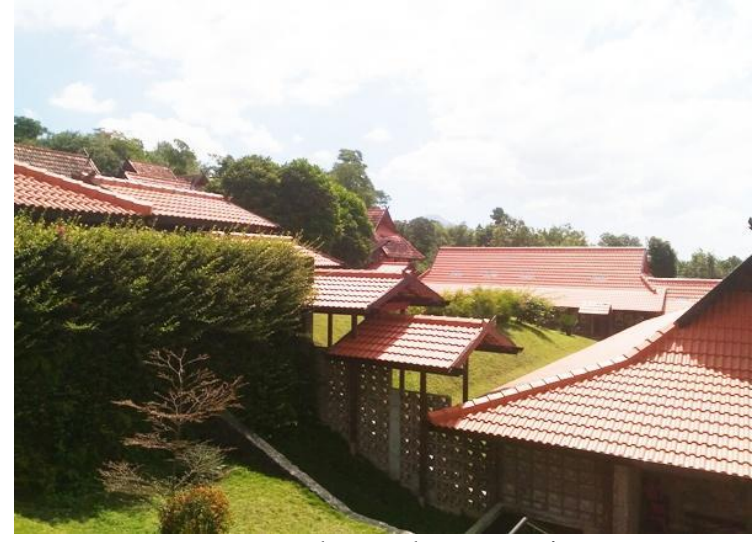

Gambar 4. Bentuk atap kmapung jompongan, perpaduan atap limasan dan atap pelana Sumber: Begini Heningnya, 2016

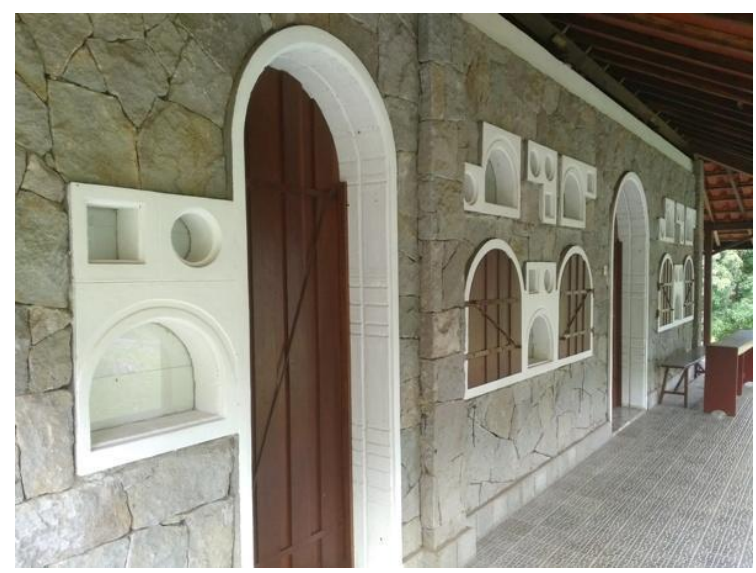

Gambar 5. Dinding menggunakan batu alam, dengan jendela dan ventilasi untuk pencahayaan dan penghawaan alami

Sumber: Begini Heningnya, 2016

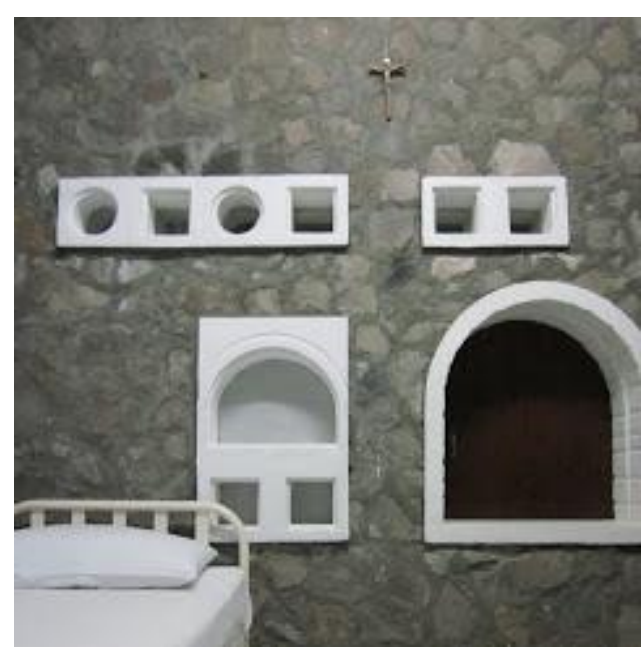

Gambar 6. Detail ventilasi dan jendela sebagai ornamen dinding

Sumber: Kisah Ziarah, 2013

\section{Edisi cetak}


Lantai pertapaan Gedono terbuat dari beton cetakan (tegel) dengan pola geometris tertentu hasil rancangan Romo Mangun sendiri. Pembuatan tegel ini diserahkan ke pihak industri masyarakat kecil dan menengah sebagai perwujudan kecintaannya pada 'wong cilik' dan sebagai bentuk pemberdayaan masyarakat sekitar.

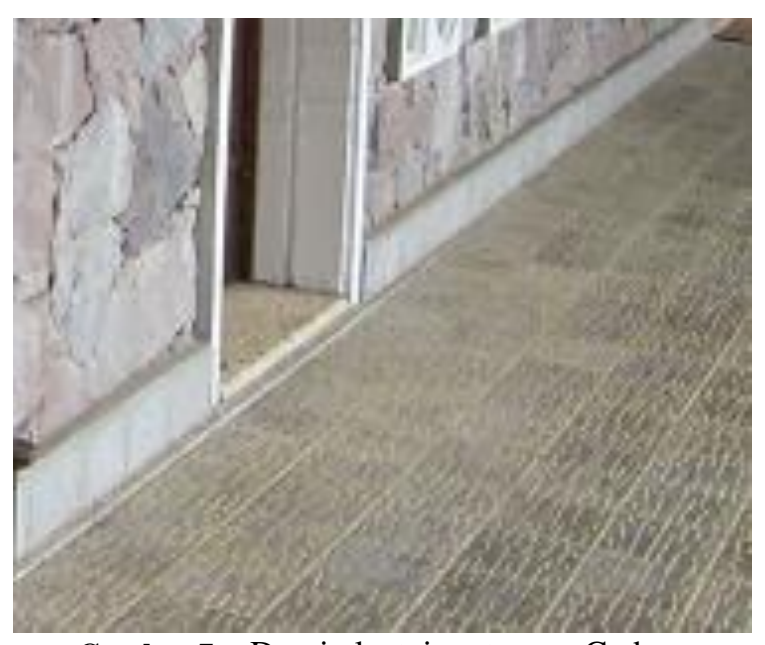

Gambar 7. Desain lantai pertapaan Gedono Sumber : Kisah Ziarah, 2013

\section{Rekonstruksi Desa Ngibikan, Bantul, Yogyakarta}

Pada tanggal 27 Mei 2006, gempa bumi melanda Indonesia di wilayah Yogyakarta. Salah satu daerah yang terkena dampak cukup parah adalah desa Ngibikan yang terletak di Kecamatan Jetis, kabupaten Bantul, Yogyakarta.

Eko Prawoto, seorang arsitek, turun tangan tak hanya untuk mendesain, tetapi sekaligus membuat perhitungan biaya, turut mengawasi kegiatan di lapangan. Semua hal tersebut atas inisiatif sendiri karena dilandasi rasa kepedulian atas nasib sesama, tanpa surat perintah dari dinas manapun, tanpa honor dari instansi manapun, bahkan tanpa himbauan dari pihak manapun. Bersama dengan Maryono tukang sekaligus ketua RT di desa Ngibikanyang merupakan rekan kerja Eko Prawoto selama ini, bahu membahu mengajak para warga dalam proses rekonstruksi ini. Alhasil dengan bantuan dana kemanusiaan yang dihimpun sebuah harian nasional, Eko Prawoto dan Maryono, bersama dengan warga desa Ngibikan berhasil menyelesaikan 65 rumah (Pangarsa, Galih W., 2008).

Model rumah tersebut kemudian dijadikan contoh dan melibatkan warga untuk selanjutnya bergotong royong secara mendiri dalam membangun rumah mereka. Desain rumah yang baru tetap mengacu pada desain bangunan yang lama, hal ini untuk menjaga kelestarian budaya yang sudah terbentuk sebelumnya.

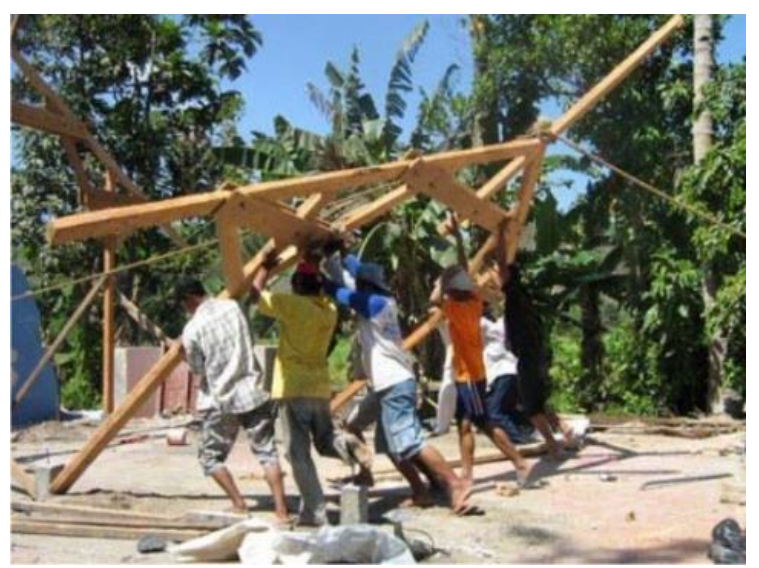

Gambar 8. Proses rekonstruksi desa Ngibikan mengandalkan budaya gotong royong Sumber: Shim, Brigitte, 2010

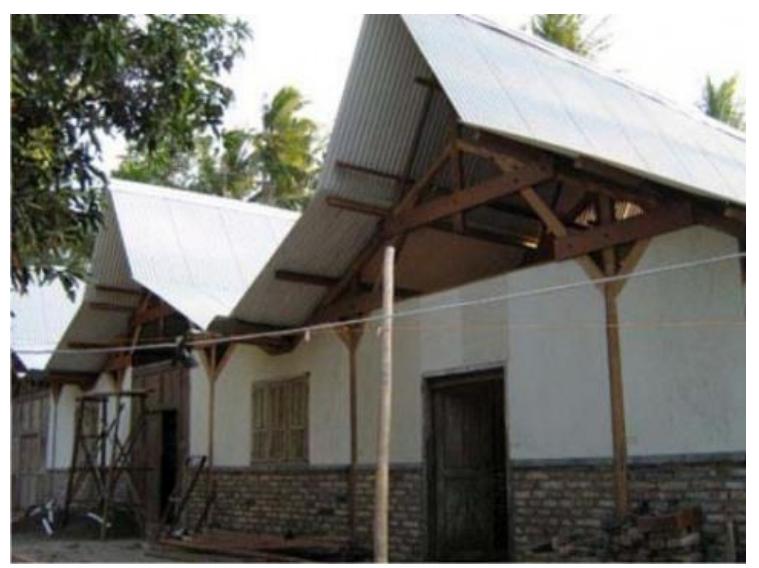

Gambar 9. Rumah hasil rekonstruksi Sumber: Shim, Brigitte, 2010

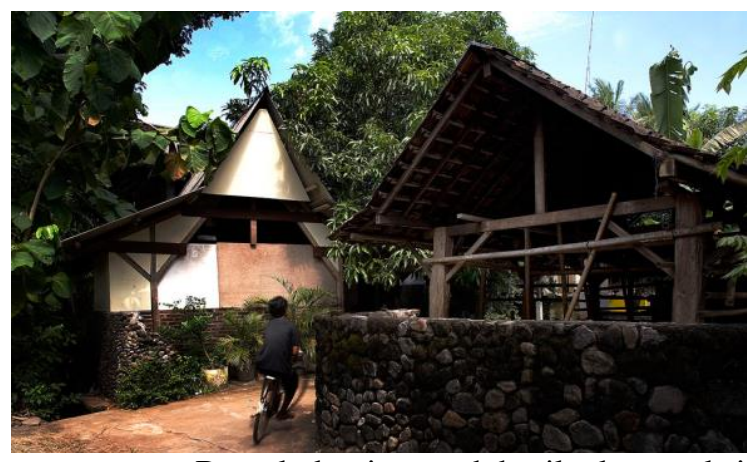

Gambar 10. Bentuk desain rumah hasil rekonstruksi tetap mengacu pada bangunan yang sudah ada Sumber: Shim, Brigitte, 2010

Proses rekonstruksi tersebut memanfaatkan material-material setempat, dan juga menggunakan sisa/bekas dari bangunan 
yang lama. Selain memanfaatkan material yang ada, hal ini diharapkan dapat meminimalisir biaya untuk rekonstruksi. Material-material yang digunakan antara lain: kayu dari pohon kelapa yang banyak terdapat di sekitar lokasi, sisa-sisa batu bata dari reruntuhan bangunan lama, jendela dan pintu juga memanfaatkan bekas bangunan yang lama.

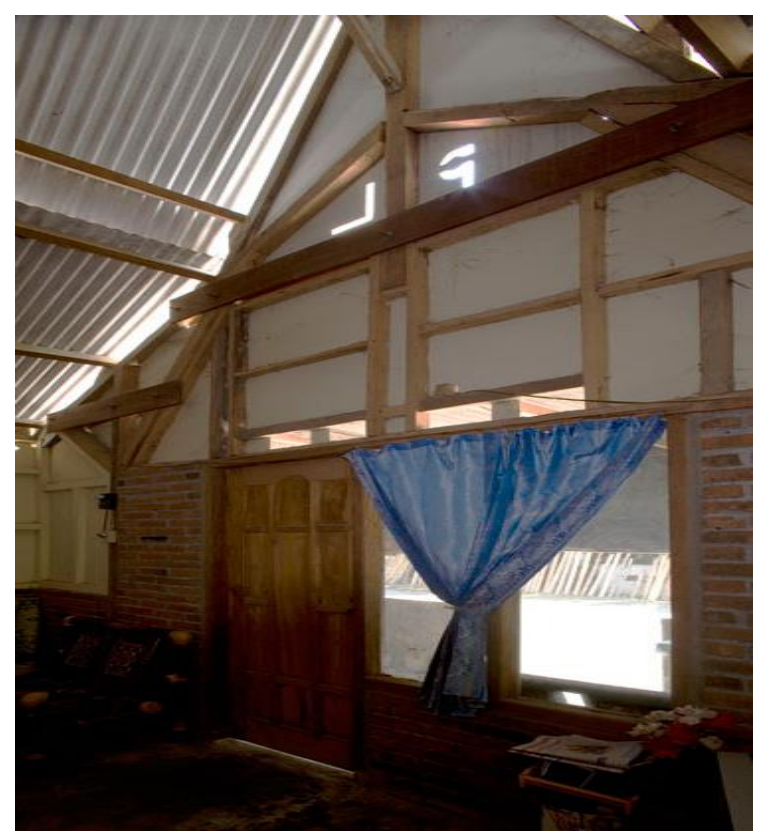

Gambar 11. Penggunaan material sisa untuk dinding dan kayu kelapa sebagai konstruksi rangka dinding dan atap

Sumber: Shim, Brigitte, 2010

Penggunaan material baru hanya pada penutup atap dan dinding atas, yaitu menggunakan bahan fibercement. Pertimbangan pengunaan bahan fibercement ini adalah untuk mendapat struktur bangunan yang ringan dan tingkat kemudahan serta kecepatan dalam proses rekonstruksi.

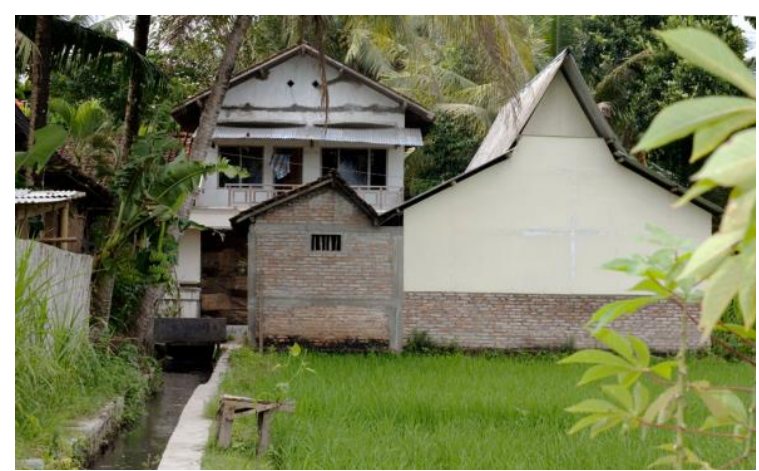

Gambar 12. Dinding bata yang dikombinasikan dengan panel dinding fibercement Sumber: Shim, Brigitte., 2010
Untuk memberi tambahan kekuatan bangunan, dibuat cor beton sebagai tumpuan kolom kayu. Penggunaan mur baut dan pasak menggantikan peran paku sebagai media sambungan antar joint. Dengan adanya perbaikan sistem struktur bangunan, diharapkan rumah hasil rekonstruksi ini nantinya akan bisa lebih tahan terhadap gempa.

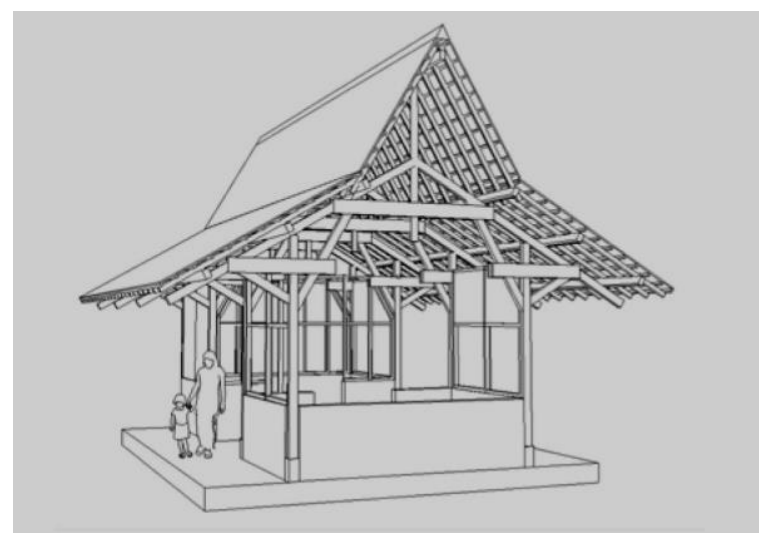

Gambar 13. Sketsa desain rekonstruksi rumah desa Ngibikan oleh Eko Prawoto

Sumber: Shim, Brigitte, 2010

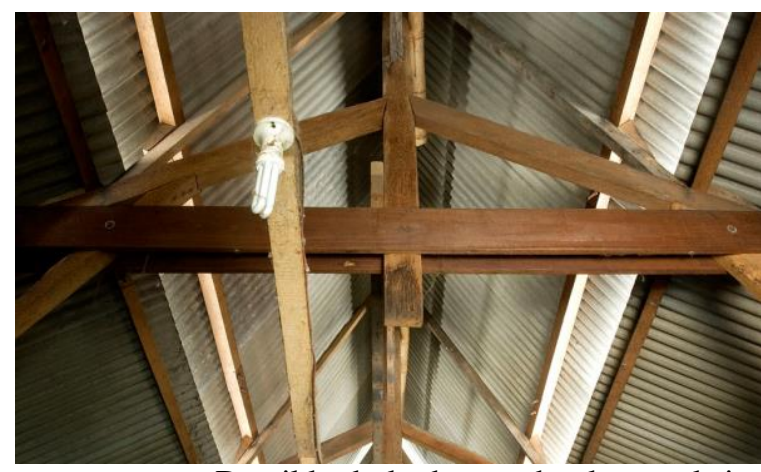

Gambar 14. Detail kuda-kuda rumah rekonstruksi desa Ngibikan

Sumber: Shim, Brigitte, 2010

\section{KESIMPULAN}

Ada hubungan yang cukup jelas antara Eko Prawoto dan Romo Mangun, yakni kedua tokoh di atas sama-sama dekat dengan masyarakat. Pemberdayaan masyarakat menjadi ciri khas dari setiap proyek mereka. Hal ini sesuai dengan ajaran Romo Mangun, di mana memberi keterampilan pada masyarakat jauh lebih bernilai dibanding jika kita hanya memberi bantuan secara materi. Arsitektur yang beradaptasi dengan lingkungan dan budaya lokal tidak hanya terbatas pada bentuk bangunannya saja, namun aspek sosial juga perlu diperhatikan dan nantinya akan menilai, bagaimana arsitektur sebagai wujud dan juga prosesnya, dapat 
bersinergi dengan alam dan lingkungan. Dari studi kasus di atas, kita dapat mengambil banyak pelajaran tentang konsep arsitektur yang berwawasan lingkungan dan memperhatikan budaya lokal. Desain bangunan yang ramah terhadap lingkungan sekitar, pemanfaatan material setempat, pemanfaatan bahan material sisa/bekas, pemberdayaan masyarakat, adalah beberapa hal yang bisa memberi gambaran konsep arsitektur yang berwawasan lingkungan dengan tetap memperhatikan budaya lokal.

Arsitektur dinilai sebagai eko-arsitektur jika mampu menciptakan kenyamanan, tidak hanya kenyamanan penghuni (manusia) namun juga kenyamanan dari alam/lingkungan di mana wujud arsitektur itu berada. Eko-arsitektur mencakup keselarasan dan keharmonisan antara manusia dengan lingkungan sekitarnya.

\section{REFERENSI}

Begini Heningnya Pertapaan Bunda Pemersatu Gedono, 2016. (http://www.kompasiana.com/bamset201 4/begini-heningnya-pertapaan-bundapemersatugedono_57bc03e4ed9673c50f3818ae), diakses tanggal 23 Desember 2016

Frick, H., (1997) Dasar-dasar eko-arsitektur, Kanisius, Yogyakarta

Halimatussadiyah dan Azhar, YK., Eko Prawoto, Arsitektur Yang Memberi / edisi Februari (2010) http://www.housingestate.com, diakses tanggal 13 Mei 2011

Hartanti, G. (2011) Penerapan Material Bahan Bangunan Dan Konsep Pemaknaan Pada Gereja Puh Sarang Sebagai Warisan Budaya Indonesia. Humaniora, 2(2), 950958.

Kisah Ziarah di Pertapaan Bunda Pemersatu Gedono (2013)

(http://detabercerita.blogspot.co.id/2013/12/kisa h-ziarah-di-pertapaan-bunda.html), diakses tanggal 23 Desember 2016

Kusbiantoro, K. (2013) Pelokalan Arsitektur Gereja di Indonesia (Studi Kasus: Gereja Maria Asumpta-Klaten Karya YB Mangunwijaya). Ambiance, 2(2).
Mangunwijaya, YB., (1988) Wastu Citra, Gramedia, Jakarta

Pangarsa, Galih W., (2008) Arsitek untuk Kemanusiaan: Teropong Visual Culture atas Karya-karya Eko Prawoto, PT. Wastu Lanas Grafika, Surabaya

Putra, R. H., \& Prijotomo, J. (2016) Pendekatan Materialitas dan Lokalitas Penggugah Kesadaran Material Bambu. Jurnal Sains dan Seni ITS, 5(2).

Shim, Brigitte., (2010) Reconstrustion of Ngibikan Village Yogyakarta Indonesia, www.landscape.cn/Special/ AgaKhan/images/r14.pdf, diakses tanggal 13 Mei 2011 